\title{
Design of Munitions Visibility Management System
}

\author{
Yu Bai ${ }^{1,2, *}$, Jingchen Zhang ${ }^{2}$, Xiangyu Qin ${ }^{2}$ \\ ${ }^{1}$ Graduate School, Space engineering University, Beijing, 101416 China \\ ${ }^{2}$ Joint Logistics Institution of NDU Beijing, 100858 China
}

\begin{abstract}
Munitions are one of the most critical and sensitive assets in the military supply chain, and its supply in the battlefield can greatly affect the result of the war. Historical data show that military forces are often provided either too much or too little ammunition because of the lack of visibility. This paper introduces the Munitions Visibility Management System that contains two parts, an organizational system and a technological system. The former one is from the administrative angle to standardize and control, and the latter one is from the technological angle to integrate and implement technologies needed. It gives a new way in studying the management of munitions.
\end{abstract}

\section{Introduction}

Munitions are high value military assets and munitions visibilities management system is part of military total asset visibility system which uses advanced technologies in tracking and monitoring munitions and doing data analyzing to grasp the munitions status in logistic supply chain, helping the munitions managers, military planner and decision-makers at various echelons to make right decisions on the munitions' employment. However, it's difficult to achieve this goal because it involves an entire military supply chain, high technologies, integration and standardization of data among military services and domestic and even international commercial sectors. [1] Thus, it is highly important to design the operational framework of organizational system and technological architecture of munitions visibility management system.

\section{The connotation of Munitions visibility management system}

As one of the military asset visibility systems, the munitions visibility management system is used to determine munitions' locations, movements, status and identity. [2] It has two facets. One is the technology facet which contains a series of cutting-edge technologies used to track and monitor, to compute and predict so as to give the relevant parties an accurate and real-time information about the munitions. The other involves administrative activities to guarantee and facilitate the effective operating of the technological systems by integrating standards, regulations and business practices together and implementing them.

From the functional point of view, the munitions visibility management system can track the munitions in the facilities and in transit, monitor the status of munitions and detect default, provide real-time information about the munitions, as well as give predictions on consumptions and requirements based on information received and historical data stored in the system.

From the user's point of view, the munitions visibility management system can provide what the users are concerned about, which includes the locations, quantities, types, and its availability. On the basis of these information, decision-makers can set priorities and conduct the allocation, warfighters can get what they need or what they are provided to fight and it is the way to deliver the right type and quantities of munitions to the right place at the right time- and the right cost.[3]

From the technological point of view, the munitions visibility management system are fusions of different kinds of technologies, which include tracking and monitoring technologies, such as IFID and sensors; communication technologies; big data; cloud-based computing technologies and Internet of Things (IoT). All these technologies are combined together to form a big system and provide real-time information.

From the development point of view, the munitions visibility management system realizes the logistics support changes from the manual work of accountability of munitions to highly automated asset accountability solution, from lag behind information to real-time picture of asset visibility, from the problem-rising and try to solve mode to predictive and prevent problem-happening mode. Therefore, it will greatly improve the effectiveness and efficiency for future battlefield munitions employment.

\section{The organizational system of Munitions Visibilities management System}

The organizational system of munitions visibility management system involves many organizations to manage and control activities and technical methods to 
implement the effective identification, tracking, monitoring, collecting data, analyzing and disseminating useful data. It is primarily contains three levels of organizations: the decision-making level organization, the regulatory level organizations, and the executing level organizations.

\subsection{Decision-making level organization}

This is the highest level of organization which can be an office under the committee for military total asset visibility. Members of this office should be top-level professionals in this field, and its principal responsibilities are outlining the munitions visibility management system development strategy, formulating munitions visibilities management guidance, promulgating a series of munitions visibilities management policies and regulations and setting and issuing standards and procedures on munitions visibilities management, defining the relevant organizations' responsibilities, standardizing the coding forms in identification systems and approving its employment, [4] controlling and assessing activities on munitions visibilities management and giving reference on problems solving.

\subsection{Regulatory level organizations}

On this level, the munitions visibilities management organizations are the offices located in military logistics sectors at various echelon of different services and military commands which can be the munitions visibility management system offices that under the leadership both from the decision-making level office and their administrative superiors. The regulatory organizations are mainly responsible for implementing the policies and regulations promulgating by the decision-making organizations, formulating the plans for munitions visibilities management in accordance with policies and regulations. They are responsible for the training of operators and managers at various level in each service and closely supervising the implementation and performance of the system, adopting operational control mechanisms and technical control mechanism to prevent risks [5] and giving the feedbacks to the decision-making level.

\subsection{Executing level organizations}

On this level, the munitions visibilities management organizations will include the users coming from the military units, depots and munitions supply points who manage the munitions information systems as well as some technical support organizations. The users can provide feedbacks on systems' performance, give practical suggestions on how to upgrade systems. Technical support organizations includes those units that participating in R\&D of munitions visibility management design, military institutions, civil-military integrated industrial complex, qualified high-tech companies, and universities and colleges from both military and civilian and manufacturers as well. They can provide technical support when the system is established and when system defaults come out, they can upgrade the system in accordance with the user's feedbacks.

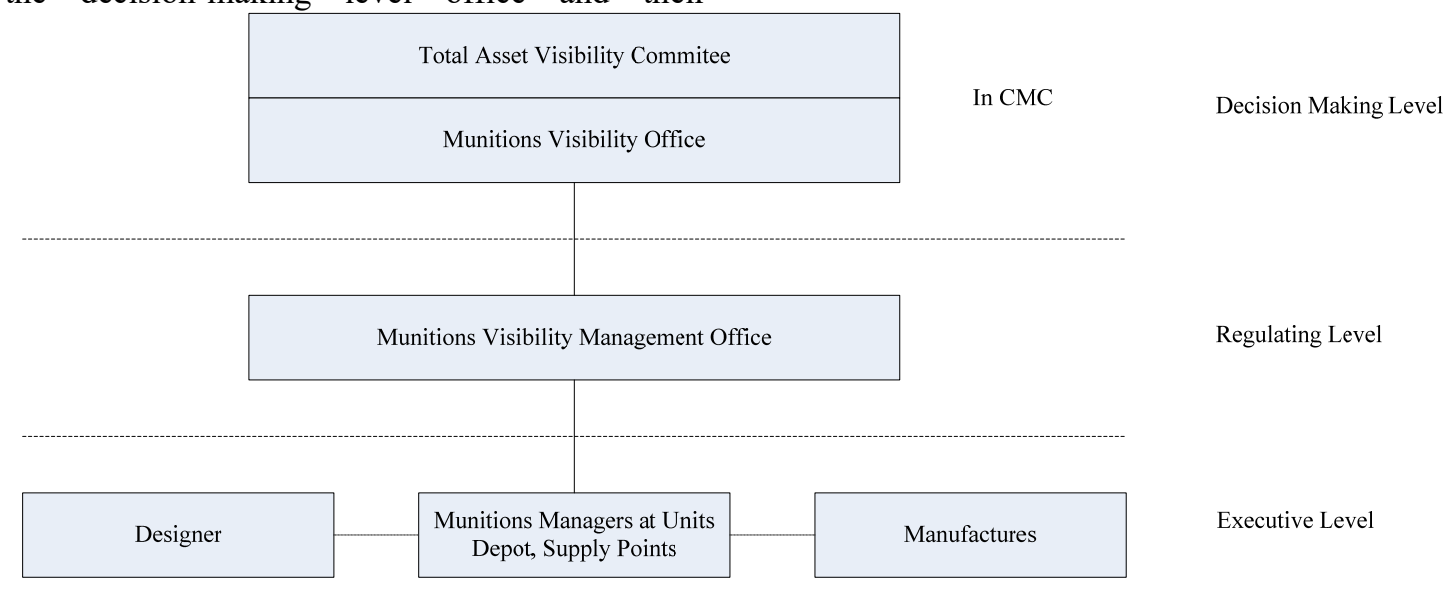

Figure 1. Organizational system of Munitions Visibilities management System

\section{The Technological Systems of Munitions Visibilities Management}

The technological system of munitions visibility management has the following aspects. Firstly, it tracks the munitions, monitors its safety status and record its movements and collects the data. Secondly, after collecting a variety of information, it begins to process it and transmit it to various munitions information systems. Thirdly, users can use the munitions information systems to predict the requirements and request the munitions, to consult the information for the storage or moving conditions, and the availability and serviceability of munitions. Lastly, there is a system integrator which integrate all the munitions information system and asset visibility systems data in the national level.

\subsection{Munitions tracking and monitoring systems}

Munitions tracking and monitoring systems are the basis for munitions visibility management. In order to distribute the right type, right quantity munitions to the right place 
at the right time, the munitions managers, the commanders and the users must acquire the information that where the munitions are, what types of them, how many of them, when to arrive. These are the basic information for them to know. Radio Frequency Identification (RFID) technology, which is widely used by commercial sectors nowadays is also adopted by advanced military as the primary technology to realize asset visibility. However, in order to effectively use such a technology system, firstly the national single standard for active or passive IFID code must be established and be used from the manufacturers to the users. Then, supporting infrastructures must be kept up with, for example, RFID readers/gateways across the important sites along the lines of communications, and etc. Lastly, the standard format for data exchange among different systems must be unified.

\subsection{Data Processing}

Data processing organization uses web-based systems and leverage satellites communications to complete the tasks of collecting the data receiving from the RFID readers or sensors, converting them in a standard format and transmitting them to the munitions information systems. Maintaining the communication is of great importance in achieving munitions visibility. However, when using the satellite, cautions must be taken on the loss of space-based communications due to the enemy's activities. Alternative communication methods can be taken to mitigate short term losses.

\subsection{Munitions information systems}

Munitions information systems are cloud-based multifunctional information systems of each military service. For units, they can be used to compute and predict munitions consumptions and requirements, and to request munitions; for munitions managers at different echelons, they can be used to consult the data of munitions inventories and stocks, to monitor the munitions safety levels, to approve the request from the units and to monitor the distribution process from the national provider to the using units. In general, all the qualified person can gain a common picture of theater munitions status by using the munitions information system, thus providing the information needed for the decision-maker of joint commands to set the priorities and allocate the munitions in accordance with the forecasting and evaluation results of relevant parties among different services.

\subsection{The national level munitions capability system}

The national level munitions capability system is an Internet of Things(IoT) based big data system, which integrates all the systems from the services and other visibility systems. It can help its users to collect, filter and organize joint munitions asset and asset visibility data, using the same data exchange format. It integrates and aggregate all services' munitions information systems' data and effectively improves data sharing among services. [6] Therefore, it has an accurate and complete data on munitions and can provide the total asset visibility over munitions. In peacetime, the services can collect and share inventory data to meet the requirement; in war time, authorized munitions managers can search for what they need in this system. For example, if a certain kind munitions are critical in the theater, they can use this system to search in the stocks of national industry base or other services' stocks for cross- levelling. In addition, when other system collapses, the national level munitions capability system can provide them the backup.

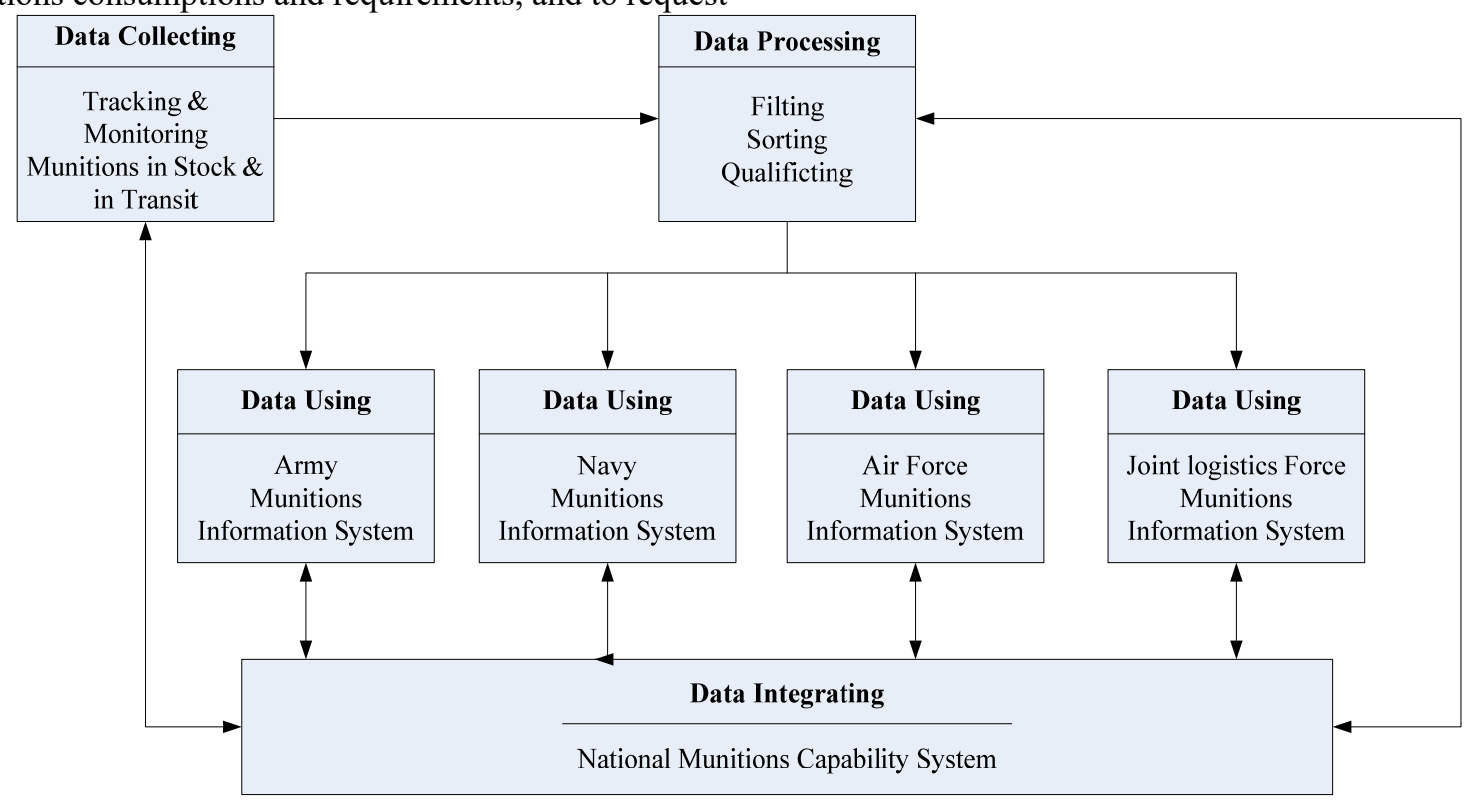

Figure 2. Technological Systems of Munitions Visibilities Management 


\section{Conclusion}

Munitions visibility management is a new management mode for munitions. It is not only a series of high-tech integration, but also a kind of advanced management practice, the result of collaborative efforts with many organizations. The two sub-systems complement each other in constructing a big system and realizing the visibility of munitions in the military supply chain, which lays a solid foundation in the precise distribution of munitions in the battlefield.

\section{References}

1. Bates, J. C. (2007) Joint Asset Visibility: Why So Hard? Journal of Army Logistician, issue 4:36-43.

2. Tapestry Solutions. (2018) Transforming the Defense Supply Chain with Internet of Things (IoT) Commercial Innovations. http://tapestrysolutions.com/wpcontent/upload/2018/12/ESI-IoT-Defense-whitepaper-Dec.-2018.pdf

3. Tapestry Solutions. (2019) Achieve Total Asset Visibility with IoT Sensor Integration \& RFIDTapestry Solutions. http:// tapestrysolutions.com/2019/05/15/transformingaerospace-defense-supply-chains-with-an-iotsensor-agnostic-integration-platform-2/.

4. Zhang, W., Lv, Y.P., Lv, H.W. and Zhao, T. (2016) Study on Identification System Framework of Military Equipment, Journal of Equipment Academy, no.4:1-4.

5. Miao H., Zhou H. (2012) The Risks and control of RFID Application in military logistics. Journal of Logistics Academy, no.4:62-64.

6. GAO, (2014) Defense logistics: Actions Needed to Improve Department-Wide Management of Conventional Ammunitions Inventory. https://www.gao.gov/products/GAO-14-182. 